\title{
Recluta para Indias. La contribución del reino de Galicia a la defensa del Imperio (1702)
}

\author{
Héctor LAgo AlmeIDa \\ Universidade de Santiago de Compostela \\ hector.lago@usc.es
}

Recibido: 16 de octubre de 2013

Aceptado: 9 de octubre de 2014

\section{RESUMEN}

Dos unidades militares de 2.000 hombres levantadas en el reino de Galicia en 1702 constituyen el objeto de la presente investigación. Se trataba de un servicio para la corona cuyo fin era la defensa del Imperio -primero Flandes y después América- en un momento en el que las convulsiones político-militares, que desencadenarían en la Guerra de Sucesión española, empezaban a aflorar. Teniendo en cuenta el contexto de transición que vivía la monarquía, descenderemos al estudio del proceso de creación de estos dos tercios: desde las negociaciones entre Felipe $\mathrm{V}$ y el órgano representativo del reino para su concesión, hasta la ejecución misma de la leva y la caracterización sociológica de los individuos que eran forzados a servir como soldados a partir del caso tudense.

Palabras clave: levas, tropa, soldados, Guerra de Sucesión española, Felipe V, tercios, América, Juntas del Reino de Galicia, Galicia, Tui, poderes locales.

\section{Recruit for the Indies. Contribution of the Kingdom of Gali- cia to the Imperial Defense (1702)}

\begin{abstract}
The object of this research is constituted by the two military units of 2,000 men created in the Kingdom of Galicia in 1702. It was a service for the crown that aimed to defend the Empire -at first in Flanders and then in America- in a moment when the military and political disturbances that would trigger the War of Spanish Succession began to emerge. Given the context of transition lived by the monarchy, we will immerse ourselves in the study of the process of creation of these two tercios: from the negotiations between Philip V and the representative institution of the kingdom for their granting, to the actual execution of the recruitment and the sociological characterization of individuals who were forced to serve as soldiers from the tudense case.
\end{abstract}

Key words: Recruitment, Troops, Soldiers, War of Spanish Succession, Philip V, Tercios, America, Juntas del Reino de Galicia, Galicia, Tui, Local Authorities. 


\section{INTRODUCCIÓN}

Sabemos que el Reino de Galicia contribuyó durante buena parte de la Época Moderna a la defensa del Imperio Hispánico, especialmente a partir de la década de 1630. En este sentido, desde los años 90 son varios los trabajos que han profundizado en este aspecto de la hasta hace poco rezagada historiografía de lo militar. Cabe destacar la labor de la profesora María del Carmen Saavedra Vázquez, cuyos trabajos han ahondado en la configuración de la primera organización militar gallega, la presión militar e integración política de Galicia en la España periférica, la financiación de la actividad militar gallega y sus repercusiones fiscales durante los siglos XVI y XVII ${ }^{1}$. Este avance ha sido completado con las aportaciones de diferentes autores, entre los que podemos destacar a Antonio J. Rodríguez Hernández. Sus investigaciones han arrojado luz sobre los sistemas de recluta y la contribución de Galicia a la defensa de los territorios flamencos en la segunda mitad del siglo XVII ${ }^{2}$. El siglo XVIII, en cambio, no ha corrido la misma suerte. Salvo recientes aportaciones de varios historiadores sobre el conflicto de la Guerra de Sucesión en Galicia ${ }^{3}$, el conocimiento que tenemos acerca de la realidad militar del reino para el resto de la centuria es muy pobre y dependiente aún de trabajos de corte tradicional.

Respecto al tema que nos ocupa en el presente artículo nos encontramos con un panorama desigual. El papel de las Juntas del Reino en su vertiente militar está parcialmente estudiado gracias a la labor desarrollada por el profesor A. Eiras Roel en el marco del proyecto de edición de las Actas de las Juntas del Reino de Galicia. En otro orden de cosas, la visión de los militares desde una perspectiva sociológica ha logrado importantes avances en el conocimiento que tenemos acerca de la realidad social de los presidios gallegos para el periodo de los Austrias ${ }^{4}$. En los estudios sobre tropa, para época borbónica, se han realizado algunos avances en forma de incursio-

1 Entre sus principales trabajos podemos citar los siguientes: Galicia en el Camino de Flandes. Actividad militar, economía y sociedad en la España noratlántica, 1556-1648. A Coruña, Ediciós do Castro, 1996; "El coste de la guerra. Características y articulación de las finanzas militares gallegas en la primera mitad del siglo XVII", Revista de historia moderna, 22 (2004), pp. 343-368; "La decadencia militar del imperio español en los Austrias: algunas consideraciones a partir del caso gallego", Semata, Ciencias Sociais e Humanidades, 23 (2011), pp. 229-251.

2 Rodríguez Hernández, A. J.: "El Reclutamiento de españoles para el Ejército de Flandes durante la segunda mitad del siglo XVII", en García Herrán, E. y MAFFI, D. (eds.): Guerra y Sociedad en la Monarquía Hispánica. Política, estrategia y cultura en la Europa Moderna (1500-1700), Vol. II, Madrid, Laberinto, 2006, pp. 395-434; "De Galicia a Flandes: reclutamiento y servicio de soldados gallegos en el ejército de Flandes (1648-1700)", Obradoiro de Historia Moderna, 16 (2007), pp. 213-251.

3 Entre otros vid. López, R. J.: "La propaganda bélica en Galicia a finales del Antiguo Régimen: de la Guerra de Sucesión a la Guerra de Independencia” en GonzÁlez Cruz, D. (coord.): Propaganda y mentalidad bélica en España y América durante el siglo XVIII, Madrid, Ministerio de Defensa, 2007, pp. 19-66; SUÁREZ Golán, F. y Lago Almeida, H.: "Conflictos y lealtades en el Reino de Galicia (1700-1714)", Rudesindus, 7 (2011), pp. 221-239; SAAVEDRA VÁZQUEZ, M. C.: "Las raíces del ejército borbónico: la perspectiva gallega", en García Hurtado, M. R.: Soldados de la Ilustración: el ejército español en el siglo XVIII, A Coruña, Universidade da Coruña, 2012, pp. 101-130.

4 SaAVedra Vázquez, M. C.: "Los militares de los presidios gallegos en la primera mitad del siglo XVII", Studia Historica. Historia moderna, 25 (2003), pp. 27-57. 
nes aisladas 5 , y lo mismo cabe decir en el caso de la oficialidad gallega durante la Guerra de Sucesión ${ }^{6}$.

Nuestro trabajo, siendo deudor de todas las investigaciones anteriormente citadas, viene a cubrir un aspecto, enmarcado a su vez en un complejo proceso, del que poco o nada conocemos. Se trata de una leva de 2.000 gallegos ejecutada en los primeros años de la Guerra de Sucesión española para la defensa de Flandes, destino que finalmente varió. Nos encontramos en un periodo un tanto especial, no solo por el conflicto bélico en sí, sino también desde el punto de vista interno de la corona hispánica. Felipe $\mathrm{V}$ era el primero de una nueva dinastía que llegaba a Madrid acompañado de aires renovadores procedentes de Francia. Sin embargo, la inmediatez de la guerra obligó a la monarquía a apoyarse en las viejas estructuras militares de los Austrias, no sin dejar ver las intenciones que poco tiempo después terminarían convirtiéndose en hechos $^{7}$. De ahí que prestemos especial atención, en primer lugar, al funcionamiento y a las negociaciones que se llevaron a cabo entre la corona y la Junta del Reino -órgano representativo de la región compuesto por los diputados de sus siete capitales de provincia- que se reunió en los primeros meses de 1702. En segundo término, trataremos de analizar el proceso de formación de las unidades militares, centrándonos especialmente en las estructuras de reclutamiento desde una perspectiva local, acercándonos también a la realidad social de los reclutados a partir del caso tudense.

Dado que la responsabilidad ejecutora de la leva giraba en torno a los poderes locales, la documentación generada por estos organismos será la base sobre la que se sustente buena parte de la presente investigación. Su importancia queda fuera de toda duda ante la ausencia de información acerca de la organización militar del reino en los archivos nacionales, especialmente para los años comprendidos entre 1699 y 1704, de ahí que la documentación local sea la única vía posible para abordar el tema. La singularidad de la documentación resulta evidente en lo que respecta a los datos recogidos acerca del perfil social de los reclutados en la antigua provincia de Tui. Se trata de una información única para el caso gallego, lo que cuanto menos matiza la escasa representatividad de la muestra en relación al conjunto de los hombres que prestaron el servicio.

\section{HERENCIA Y PRIMERAS NECESIDADES}

A pesar de que la península quedó al margen de los enfrentamientos en los primeros años de la Guerra de Sucesión, la recluta de hombres y la movilización de recursos internos se convirtieron en medidas imprescindibles para hacer viable la defensa del

5 Vid. Rey Castelao, O.: "Hombres y ejército en la Galicia del siglo XVIII", en Vázquez Varela, J. M. (et. al): A Guerra en Galicia: o rural e o urbano na historia de Galicia, Santiago de Compostela, Asociación Galega de Historiadores, 1996, pp. 153-188.

6 SaAvedra Vázquez, M. C.: "La elite militar del Reino de Galicia durante la Guerra de Sucesión", en López Díaz, M. (ed.): Elites y poder en las monarquías ibéricas. Del XVII al primer liberalismo, Madrid, Biblioteca Nueva, 2013, pp. 223-244.

7 Andújar Castillo, F.: "La reforma militar en el reinado de Felipe V", en Pereira Iglesias, J. L. (coord.): Felipe V de Borbón, 1701-1746, Córdoba, Universidad de Córdoba, 2002, pp. 615-640. 
imperio en Europa. Desde 1702 Felipe V había tratado de impulsar una reforma orgánica del ejército en base al modelo francés ${ }^{8}$, que culminaría en las famosas ordenanzas de 1704, a pesar de que las emergencias de la guerra terminaron por abrir la vía del "continuismo austriaco" a la hora de crear las nuevas unidades que se encargarían de la defensa de la península9.

Al mismo tiempo que se acometían esas reformas, en los primeros años de la contienda se trató también de incrementar el número de tropas encargadas de la defensa de la monarquía. Dado que hasta 1704 la península vivió la guerra con cierta tranquilidad, salvo por los ataques a la bahía de Cádiz y a la ría de Vigo en $1702^{10}$, no se ejecutó una recluta de gran envergadura hasta 1703, con la aplicación de la real ordenanza "del uno por ciento" -que obligaba al enganche de un hombre por cada 100 en Castilla. Sin embargo, un año antes, previo estallido oficial de la guerra, se había procedido a una primera movilización. El 2 de enero de 1702, Felipe V redactaba una Real Cédula, cuyo destinatario era el Príncipe de Barbanzón, capitán general del Reino de Galicia, en la que se convocaba a la Junta del Reino ante la necesidad de hacer una leva para Flandes ${ }^{11}$.

Tal contribución a la defensa de las posesiones flamencas constituía en cierto modo una tradición, cuyas raíces se hundían en la década de 1630, momento a partir del cual Galicia funcionó como base de las primeras expediciones marítimas a Flandes ${ }^{12}$. El incremento de la presión militar sobre el Reino no fue una excepción, sino que se trataba de un segmento más del engranaje militar de la monarquía, lo que sí resultaba excepcional fue la proporción de hombres reclutados derivada de la potencialidad humana de la región ${ }^{13}$. Así, la etapa comprendida entre 1637 y 1668 estuvo marcada por un largo periodo de guerra interna, a la vez que la espina dorsal sobre la que se había asentado el potencial militar hispano sufría una dura crisis demográfica y económica. Este contexto determinó que, territorios hasta el momento considerados "periféricos" y/o protegidos por sus fueros, se viesen obligados a participar de la movilización de recursos para la guerra ${ }^{14}$.

Las obligaciones en tiempos de guerra se magnificaron en un momento en el que, además, los sistemas de reclutamiento estaban empezando a manifestar cambios. Era evidente que cada vez tenía más peso la vía de las levas forzosas - en detrimento de

8 Ibidem, pp. 615-640; Ribot García, L.: "Las reformas militares y navales en tiempo de Felipe V", en Maza Zorrilla, E., "y otros": Estudios de Historia. Homenaje al profesor Jesús María Palomares, Valladolid, Universidad de Valladolid, 2006, pp. 129-161.

9 Tal es el caso de las unidades levantadas en Galicia. Vid. SaAvedra Vázquez, op. cit. (nota 4), pp. 120 y ss.

10 Vid. González Beltrán, J. M.: El asalto anglo-holandés a la Bahía de Cádiz entre la política internacional y las repercusiones locales, Puerto de Santa María, Concejalía de Cultura, 2003; KAMEN, H.: "The destruction of the Spanish Silver Fleet at Vigo in 1702", Historical Research, 29 (1966), 165-173.

11 Actas de las Juntas del Reino de Galicia (AJRG), vol. XII, 2/I/1702, 8-B, p. 418.

12 La situación geográfica de Galicia y la buena salud demográfica que vivió el reino lo convirtió en el vivero perfecto de hombres durante el siglo XVII. Vid. SAavedra VÁzQuez, op. cit. (nota 1).

13 A lo largo del reinado de Carlos II del conjunto de los reclutas que fueron enviados desde la corona de Castilla alrededor de un 49\% procedían de Galicia. Rodríguez Hernández, op. cit. (nota 2), 2006, p. 429.

14 Thompson, I. A. A.: "La movilización de los recursos nacionales y la tesis de Downing. La guerra y el Estado en España a mediados del siglo XVII", en Martínez Ruiz, E. y Pi Corrales, M. P. (dirs.): España y Suecia en la Época del Barroco (1600-1660), Madrid, Consejería de Educación y Cultura, 1998, pp. 281-283. 
la presencia de soldados voluntarios- y que la pérdida del monopolio de la corona en materia de reclutamiento estaba recayendo sobre los poderes locales ${ }^{15}$. Tales circunstancias crearon un marco en el que la monarquía había conseguido redistribuir esfuerzos en materia militar durante todo el siglo XVII alimentando la concreción de un sistema de reclutas del que Felipe V se sirvió para desarrollar las primeras movilizaciones para la guerra ${ }^{16}$.

Por tanto, la vía de reclutamiento indirecto ganó peso, en tanto que cada vez era más necesaria la intermediación de los órganos representativos de los reinos, así como de las provincias y los municipios, para poder completar las filas de las tropas. La provincialización del sistema de reclutas provocó que el coste económico de levantar unidades se distribuyera entre estos territorios y la monarquía, aunque es cierto que la capacidad negociadora de las élites periféricas en relación con la corona se vio enormemente potenciada. En cualquier caso, también hay que tener en cuenta que no siempre se contó con el beneplácito de los órganos representativos, bien por negarse abiertamente al servicio -lo que no fue habitual-o porque desde la autoridad monárquica se prescindió de su capacidad decisoria, con lo que se evitaban los tira y afloja de las negociaciones. Un ejemplo lo tenemos en el Reino de Galicia, que aportó hombres sin la necesidad de convocar Juntas en 1672 y en $1684^{17}$, negociando la corona directamente con las provincias. Más ilustrativo si cabe es el caso del Reino de Valencia, cuyos servicios de hombres fueron tramitados a través de una Junta de Leva a partir de 1645, haciendo viable la recluta sin la necesidad de convocar Cortes ${ }^{18}$.

\section{ENTRE EL REINO Y EL REY: TRAMITACIÓN Y CONCESIÓN DEL SERVICIO}

El dos de enero de 1702 Felipe V llamaba a 2.000 gallegos a la defensa de Flandes. La cercanía geográfica y la predisposición anímica, según algunas interpretaciones ${ }^{19}$, de los gallegos para la defensa de Flandes fue seguramente lo que determinó que una de las primeras medidas que se tomaron para la salvaguarda del Imperio fuera la promulgación de la Real Cédula para la convocatoria de la Junta del Reino ${ }^{20}$. Eran las Juntas las que habitualmente servían de llave para la concesión de soldados. La convocatoria de las Juntas por parte de los monarcas en aquellos momentos en los que se necesitaba una leva urgente y/o numerosa resultaba de gran utilidad, ya que en sus

15 Contreras Gay, J.: "El siglo XVII y su importancia en el cambio de los sistemas de reclutamiento", Studia Historica, Historia Monderna, 14 (1996), pp. 141-154; Thompson, I. A. A.: "El soldado del Imperio: una aproximación al perfil del recluta español en el Siglo de Oro”, Manuscrits, 21 (2003), pp. 23 y ss. No fueron cambios exclusivos de los ejércitos españoles, sino que fue una tendencia extensible a toda Europa. Vid. TAllett, F.: War and society in Early-Modern Europe, 1495-1715, Londres, Routledge, 1992, p. 73.

16 Andújar Castillo, F.: El sonido del dinero: monarquía, ejército y venalidad en la España del siglo XVIII, Madrid, Marcial Pons, 2004, pp. 45 y ss.

17 Rodríguez Hernández, op. cit. (nota 2), 2007, p. 234.

18 Candela Marco, M. V. y Fernández Nadal, C. M.: "La guerra en movimiento: los valencianos en Italia durante el reinado de Carlos II", Millars: Espai $i$ historia, no 26 (2003), pp. 209-210.

19 Rodríguez Hernández, op. cit. (nota 2), 2007, p. 248.

20 Vid. supra nota 11. 
reuniones se tomaban acuerdos vinculantes para todos los partidos del reino, lo que suponía una enorme ventaja en un territorio altamente señorializado ${ }^{21}$. Habitualmente la petición de hombres iba seguida de un proceso de negociación entre las Juntas del Reino y las autoridades monárquicas en el que los representantes de las siete ciudades gallegas trataban de obtener ciertos privilegios a cambio de la ejecución del servicio.

En la Real Cédula se dejaba claro tanto la financiación que sustentaría la creación de las unidades militares como las instrucciones para la ejecución de la recluta. Sobre el papel rezaba inicialmente una financiación que recaía en su práctica totalidad sobre la hacienda real, salvo los propios costes originados por la prisión y desplazamiento de los individuos hasta el punto de partida - que se sobrentendía que corrían a cuenta de las entidades locales. Entre las contribuciones de la corona estaba el compromiso de enviar los vestidos para la tropa, a excepción de las camisas y corbatas que tenían que ser fabricadas por el reino. El grueso de la contribución gravitaba sobre los gastos que originaban los sueldos y las raciones de la oficialidad y la tropa generadas en la ciudad de A Coruña - punto de encuentro habitual de las tropas-, mientras no fuesen embarcadas hacia Flandes. A estos se sumaban los gastos derivados del flete de las embarcaciones, lo que suponía una suma de 42.000 escudos de vellón sacados "del producto de las alcabalas, çientos, servicios de millones y rentas de salinas de ese Reyno"22.

Hasta aquí, la propuesta inicial del monarca no introducía grandes cambios con respecto a las demandas anteriores. No ocurre lo mismo en la segunda parte de la cédula en la que se advierte que "los capitanes y ofiçiales que vinieren de Flandes a la recluta [...] se encarguen della y atiendan a su coserbación y custodia". De un plumazo y en la primera petición de un servicio que realizaba la corona bajo Felipe $\mathrm{V}$, se prescindía de la libre elección de la oficialidad que habitualmente solía conceder la corona a las capitales de las provincias. Aunque no se trataba de una total novedad, pues en contadas ocasiones se procedió del mismo modo durante el reinado de Carlos II, esta limitación inicial de las prerrogativas que habitualmente obtenían las Juntas da cuenta de la nueva política de inspiración francesa que se pretendía llevar a cabo, pese a que la inmediatez de la guerra impidió la culminación de cualquier reforma de gran calado en el reino ${ }^{23}$.

A finales de enero, las capitales de provincia recibieron la convocatoria por mano del Príncipe de Barbanzón, capitán general del reino y máximo representante de la corona en Galicia ${ }^{24}$. Las reuniones de las Juntas comenzaron a principios de marzo y el ocho del mismo mes cada una de las ciudades pronunció su voto sobre la concesión de los 2.000 hombres. Las siete ciudades concedieron por unanimidad el servicio, seguido de las habituales peticiones como contraprestación al servicio. A todas luces, el punto de concordancia entre todas era la concesión de las patentes en blanco para

21 C fr. Artaza Montero, M. M.: Rey, reino y representación. La Junta General del Reino de Galicia, Madrid, CSIC, 1998, pp. 269 y ss.

22 AJRG, vol. XII, 2/I/1702, 8-B, p. 419

23 Vid. SaAvedra Vázquez, op. cit. (nota 4), pp. 101-130. De la misma autora y con especial atención al nombramiento de la oficialidad: op. cit. (nota 6), pp. 233 y ss.

24 Archivo Histórico Provincial de Pontevedra (AHPPo), Concello de Tui (CT), L-823, 18/I/1702, ff. 69r-70r. 
el nombramiento de la oficialidad. El voto más laxo fue el expresado en bloque por los representantes de Coruña, Betanzos, Lugo, Mondoñedo y Ourense, en el que proponían un nombramiento compartido entre corona y reino, de forma que uno de los tercios de mil hombres quedara bajo la custodia y mando de los oficiales flamencos y el segundo bajo una oficialidad nombrada entre los naturales, incluidos los puestos de maestre de campo y sargento mayor ${ }^{25}$. No quedó sin mencionar la tradicional petición del tanteo de las rentas de alcabalas y millones por doce años, junto a la concesión de la merced de grandeza para el reino.

Los votos de los representantes de las ciudades de Tui y Santiago recogieron también el sentido general de las restantes provincias, con algunos matices derivados de la propia realidad de cada una de éstas. Tui, por su lado, después de una reflexión en la que aludía al decadente estado de las defensas del reino en caso de un ataque por mar y/o por tierra ${ }^{26}$, reclamaba el nombramiento de todos los mandos, "tanto por grateficar con este favor la prontitud con que se an exercitado en el real servicio quanto por la conbeniençia de que los soldados vayan bajo la mano de aquellos que [...] les an de tratar con el cariño correspondiente”. Además, también pedía la supresión y/o reducción de las milicias, de hecho, con anterioridad, en gran parte de las concesiones de servicios su voto había pivotado sobre la misma idea. Desde el fin de la Guerra de Restauración portuguesa la defensa preventiva de la frontera sur de Galicia había recaído sobre los naturales de las provincias limítrofes, que para el caso de Tui suponía el mantenimiento constante de 450 hombres distribuidos entre diferentes plazas que salpicaban la ribera del Miño y la margen sur de la Ría de Vigo ${ }^{27}$.

El representante compostelano, además de recalcar la misma idea acerca de la concesión de la totalidad de las patentes, puso el acento sobre el procedimiento reclutador. Además de las previsibles apreciaciones sobre la conformidad de que los apresados fuesen en primer lugar los que "an comido sueldo y los oçiosos", se llamaba la atención sobre el reemplazo de las bajas, tanto por deserción como por muerte. Habitualmente el reemplazo le correspondía a la provincia de origen del soldado en cuestión, no obstante, en el caso de Santiago se puntualizaba que una vez entregados los sujetos a los reales oficios e independientemente de las bajas que estos tuvieran, ni la ciudad ni su provincia se hacían responsables de su substitución. Asimismo, estos soldados serían enviados con sus propias vestimentas, limitando todo gasto a mayores del generado por la misma recluta y transporte a Coruña ${ }^{28}$. Todas estas precisiones resultan más comprensibles si tenemos en cuenta que la provincia más poblada del reino era la de Santiago y por tanto era la que mayor número de hombres tenía que aportar.

Siguiendo lo dispuesto por el voto del diputado compostelano, unánimemente acordaron la ejecución de la leva y la distribución de las órdenes para llevarla a cabo en la noche del 24 de marzo. No dejaron de lado las contraprestaciones que esperaban

25 AJRG, vol. XII, 8/III/1702, 91-A, pp. 253-254.

26 La inexistencia de un conflicto "doméstico" desde el fin de la Guerra con Portugal se había puesto de manifiesto en el perceptible anquilosamiento del sistema defensivo gallego. AJRG, vol. XII, 8/III/1702, 91-A, p. 255.

27 AJRG, vol. XII, 8/III/1702, 91-A, p. 256.

28 AJRG, vol. XII, 8/III/1702, 91-A, p. 252. 
recibir de la corona a cambio de la concesión del servicio ${ }^{29}$, por ello elevaron una súplica en la que reivindicaban que se mantuviera "la posesoria en que se alla el R.o de proveer los oficiales que se conçideran precissos para los dos mil ombres" y, si no fuera el caso, "el consuelo de llevar las patentes de diez capitanes, la de un sargento maior y la de un mre. de canpo" ${ }^{30}$. A esto se le añadía también el tanteo de las rentas de alcabalas y millones, junto a la concesión de la merced de grandeza.

La desazón de los representantes gallegos, ante la resistencia de la corona a conceder las patentes, no pasó desapercibida en las siguientes sesiones de la asamblea que se alargaron hasta principios del mes de mayo. Un hecho compresible si se tiene en cuenta que este privilegio constituía una práctica que hundía sus orígenes en el 1637, en un contexto en el que las urgencias bélicas y las crisis del sistema de recluta estaban socavando la capacidad militar castellana. Felipe IV había accedido a que los nombramientos de la oficialidad recayeran sobre los candidatos de las siete ciudades, no así de la plana mayor, cuya elección no fue concedida hasta $1689^{31}$. De cualquier modo, no se podía entender como una concesión graciosa aneja a la recluta de soldados en Galicia, pues al igual que no siempre se optó por la convocatoria de las Juntas para la obtención de hombres, tampoco se brindó continuamente a las ciudades la posibilidad de nombrar los cargos. Al igual que tampoco se puede sobredimensionar este elemento estimulador para la recluta, ya que hubo ocasiones en las que las elites gallegas se negaron a levantar nuevas unidades a pesar de que la corona cediera todas las patentes en blanco ${ }^{32}$.

Finalmente, antes de que se cumpliera un mes desde el inicio de las negociaciones, la corona acabó concediendo la nominación de las patentes de capitanes y sus subalternos $^{33}$. Pese a ello, no cejaron en su empeño de lograr también la elección de los mandos enviando una segunda súplica que en ningún caso fue tenida en cuenta; de hecho, los nombramientos de las sargentías mayores ya habían sido efectivos en las personas de D. Felipe Mayo y D. Alonso Felipe de Andrade ${ }^{34}$. Tras varias sesiones el monarca terminó por enrocarse en una segunda propuesta, en la que volvía a insistir sobre la resolución de los mandos, se dejaba en el aire el tratamiento de grande y se obviaba la cuestión de las rentas, a la vez que se ordenaba la disolución de las Jun$\operatorname{tas}^{35}$.

Fuera de tales consideraciones, la tensión y la frustración de los representantes gallegos también estaban originadas por el cambio de destino de las tropas hacia el continente americano ${ }^{36}$, con la que se buscaba compensar la presencia de la armada anglo-holandesa en América. De ahí que desde los primeros meses de 1702 se pusiese en marcha un dispositivo con el que se pretendía asegurar las defensas imperiales en el Atlántico. Dada la debilidad de la armada hispánica, fue la francesa la que estuvo

29 Cfr. Eiras Roel, A.: "Introducción histórica", en Actas de las Juntas del Reino de Galicia, Vol. XII (1701-1704), Santiago de Compostela, Xunta de Galicia, 2003, p. 43.

30 AHPPo, CT, L-823, 11/III/1702, f. 83r.

31 Artaza Montero, op. cit. (nota 21), pp. 289-290.

32 Vid. SaAvedra VázQuez, op. cit. (nota 6), pp. 227-228.

33 AJRG, vol. XII, 18/III/1702, 10-B, p. 420.

34 AJRG, vol. XII, 28/III/1702, 63-D, p. 623.

35 AJRG, vol. XII, 24/IV/1702, 12-B, pp. 422-423.

36 AJRG, vol. XII, 17/III/1702, 9-B, p. 419; 28/III/1702, 63-D, p. 622. 
1lamada a realizar diversas acciones militares en aguas americanas ${ }^{37}$. La armada francesa del almirante Jean-Baptise Ducasse tendría que cubrir la ruta entre A Coruña y Veracruz, y mientras esta se encargaba de salvaguardar la tranquilidad marina, los tercios gallegos estarían destinados a asistir la defensa terrestre del continente. Los 2.000 hombres deberían embarcar en A Coruña, dividiendo a los soldados en dos cuerpos de mil cada uno y a su vez en diez compañías de 100. A mayores el reino se tendría que encargar de prevenir el abastecimiento correspondiente a setenta días de viaje a costa de los recursos de la monarquía, sin especificar exactamente el origen de la financiación ${ }^{38}$.

La excepcionalidad de la medida no es nada desdeñable a la hora de integrarla en la política defensiva que hasta el momento se había llevado a cabo en América. Hasta finales del siglo XVII la creación de unidades de refuerzo enviadas desde la península no distaba del sistema de recluta utilizado para Flandes o para Italia, si bien es cierto que en su mayor parte eran ejecutadas en Andalucía, lo cual era en parte lógico por la proximidad de Cádiz, puerto de embarque de todas las expediciones a América ${ }^{39}$. Desde el punto de vista cuantitativo, a excepción de expediciones concretas, como la realizada en 1699 para la recuperación de Darién ${ }^{40}$, las unidades enviadas no solían ser de más de unos pocos centenares, de hecho era normal que se trasladasen solamente restos de unidades para completar otras en las Indias. En este sentido, la creación de dos unidades ex profeso para América, con un número y procedencia que rompía con lo habitual, se vincula en mayor medida con las iniciativas militares desarrolladas en el siglo XVIII ${ }^{41}$.

La reacción de los representantes gallegos ante el cambio de destino no se hizo esperar, pues organizaron una junta de teólogos y juristas de la que resultó el acuerdo de realizar consultas y súplicas al monarca, amén de a otras personalidades con capacidad de presión, entre los que estaban el Virrey y Capitán general de Cataluña, el Conde de Palma, y D. Gregorio de Mella, miembro del Consejo de Guerra y veedor general del reino ${ }^{42}$. El discurso de todas las misivas giraba en torno a la idoneidad del soldado gallego en el contexto bélico flamenco, en el escaso nivel de deserciones y en lo "dilatado y penoso" que era el viaje hacia América. Además, hacía hincapié en que su tradicional presencia habría demostrado la importancia que tenía para "las armas la naçión gallega y averse proporçionado siempre su complexión al clima de los países de Flandes"43.

Más allá de considerar tales apreciaciones como una interpretación fundada o más como un recurso disuasorio, o ambos, la asamblea gallega trató de ejecutar un movi-

37 Martínez Shaw, C.: "La Guerra de Sucesión en América”, en García GonzÁlez, F. (coord.): La Guerra de Sucesión en España y la Batalla de Almansa: Europa en la encrucijada, Madrid, Sílex, 2009, pp. 77-78.

38 AJRG, vol. XII, 17/III/1702, 9-B, p. 420.

39 Marchena Fernández, J.: Oficiales y soldados en el Ejército de América, Sevilla, CSIC, 1983, pp. 271 y ss.

40 Vid. Storrs, C.: "El “desastre” de Darién (1698-1700). La pervivencia del poder imperial español en el ocaso de la España de los Habsburgo", Revista de Historia Naval, 68 (2000), pp. 7-34.

41 Marchena FernándeZ, op. cit. (nota 39), pp. 337-338.

42 Cfr. Eiras Roel, op. cit. (nota 29), p. 44. AJRG, vol. XII, 3/IV/1702, 96-A, p. 269.

43 AJRG, vol. XII, 3/IV/1702, 66-D, pp. 626-627. 
miento político ejerciendo una cierta presión directa, e indirecta a través de terceros, de la que sin embargo no obtuvo ningún resultado.

A la altura del mes de junio partía desde A Coruña la armada del general Ducasse acompañado de 2.000 hombres y del duque de Alburquerque, D. Francisco Fernández de la Cueva, futuro virrey de Nueva España, que exageradamente interpretaba que tenía como compañeros de viaje a 10.800 soldados reclutados en Galicia ${ }^{44}$. No podemos afirmar con seguridad el destino último de las dos unidades, sin embargo, algunas noticias aisladas que llegaron desde América por mano del gobernador de Cartagena de Indias ${ }^{45}$, señalaban que a finales del verano de 1702 la escuadra de Ducasse había llegado a esta ciudad con cinco compañías de infantería compuestas por catorce oficiales y 404 soldados llegados desde la península. Con toda seguridad estas compañías disminuidas - habían perdido casi una quinta parte de la tropa- serían las reclutadas en Galicia que, después de su paso por Veracruz, se habían trasladado a Cartagena, en donde las tropas se agregaron temporalmente a los presidios de la ciudad, para dirigirse a posteriori a Portobelo y Panamá.

\section{FORMACIÓN DE LAS UNIDADES Y EJECUCIÓN DE LA LEVA}

Entretanto el Reino procuraba capear el cambio de rumbo hacia América, el proceso de creación de las dos unidades ya se había puesto en marcha. Cabe distinguir en este proceso una doble dimensión en la que intervendrán factores y mecanismos diferenciados: por un lado, la propuesta de la oficialidad, y por otro, la prisión de la tropa. Considerando lo primero un privilegio y/o compensación de lo segundo, las patentes eran repartidas entre las siete cabezas de provincia en función del número de soldados que cada una tendría que aportar, basándose este reparto en el método de tercias y sextas partes. Para el caso que nos toca tan solo se había concedido la nominación de capitanes y sus subalternos. Estos serán designados por las respectivas capitales, que habitualmente solían beneficiar a sus propios integrantes ${ }^{46}$, limitando las posibilidades de elección de todas aquellas localidades que no fuesen capitales de provincia ${ }^{47}$. Las elites locales habían logrado por este proceso una vía de ascenso social independientemente de que tuviesen o no experiencia en el manejo de las armas. En cualquier caso, hay que llamar la atención sobre el hecho de que los conflictos militares de la

\footnotetext{
44 Navarro García, L.: "La participación de México en la Guerra de Sucesión Española", en La guerra de Sucesión en España y América. X Jornadas Nacionales de Historia Militar, Madrid, Deimos, 2001, p. 282.

45 Ruíz RiverA, J. B.: "La defensa de Cartagena de Indias durante la Guerra de Sucesión”, en ibidem, pp. 302-303.

46 En el caso de Tui, uno de los capitanes que se nombró fue D. Alonso Correa Medoza y Sotomaior, regidor perpetuo y diputado por aquel entonces en la Junta del Reino. AHPPo, CT, L-823, 22/III/1702, f. 189r.

47 Un hecho que contrasta con el caso de las provincias vascas y con el asturiano, en donde, si bien había un predominio de las capitales provinciales en el nombramiento de la oficialidad, las hermandades y jurisdicciones con cierta importancia reclamaban su cota de poder a la hora de elegir los mandos de las unidades que se formaban en estos territorios. Truchuelo García, S.: "El deber de servicio militar al monarca: los casos alavés y guipuzcoano (siglos XVI-XVII)", Iura Vasconiae, 4 (2007), pp. 257 y ss; RodríGUEZ HERNÁNDEZ: Los Tambores de Marte. El reclutamiento en Castilla durante la segunda mitad del siglo XVII (1648-1700), Valladolid, Universidad de Valladolid, 2011, p. 248.
} 
segunda mitad del XVII habían generado el caldo de cultivo propicio para la proliferación de una élite gallega con experiencia en el terreno militar, al calor también de las posibilidades que se habían abierto con la cesión de las patentes en blanco ${ }^{48}$.

\subsection{EL ENTRAMADO RECLUTADOR: ¿UNA DISTRIBUCIÓN EQUILIBRADA?}

No cabe duda que los cambios en el sistema de reclutas que tuvieron lugar en el siglo XVII incrementaron la fiscalidad bilateral sobre las autoridades locales ${ }^{49}$, a la vez que estas se incorporaban al entramado reclutador de la monarquía adquiriendo por tanto una cota de poder. Como ya se ha señalado, el origen estaría en la crisis del reclutamiento de voluntarios, lo que obligó a la corona a poner en marcha mecanismos de colaboración sobre los reinos y territorios que tradicionalmente poco habían contribuido a engrosar las filas de los ejércitos, siempre en comparación con la presencia superlativa de hombres castellanos y/o andaluces. En 1702 el Príncipe de Barbanzón ya partía de la "ynposibilidad de que se consiga voluntaria", un hecho que la experiencia del siglo anterior había demostrado en varias ocasiones ${ }^{50}$, abriendo la vía a los métodos coercitivos de reclutamiento. Si bien por lo que respecta a Castilla la sustitución de la recluta voluntaria por la forzosa se ha vinculado, en buena medida, a la crisis demográfica y económica del seiscientos ${ }^{51}$, para el caso gallego -con una trayectoria divergente y conocida ${ }^{52}-$ se recurre a aspectos de tipo estructural, por ser la modalidad de recluta voluntaria eminentemente de aplicación urbana ${ }^{53}$, lo que chocaba de lleno con la realidad de las ciudades y villas del noroeste peninsular, enormemente débiles en cuanto a sus efectivos demográficos.

Por tanto, haciendo extensible esta misma circunstancia al resto de la cornisa cantábrica, la única vía que podría permitir ampliar la contribución de soldados a todo el territorio pasaba inevitablemente por la colaboración de las entidades locales, desde las capitales de provincia, pasando por las cabezas de partido y hasta llegar en última instancia a las múltiples jurisdicciones o las parroquias; en el caso alavés a través de las hermandades o en Asturias por medio de sus concejos ${ }^{54}$. Este entramado fue el que posibilitó la creación de unidades militares con un volumen formidable de soldados que de otro modo no sería posible obtener en estos territorios, en tanto en cuanto la participación de los poderes locales permitía una recluta diligente y sin grandes

\footnotetext{
48 SAAVEdRa VÁzQUEZ, op. cit (nota 6), p. 239.

49 Thompson, op. cit. (nota 14), pp. 290-291.

50 SaAvedra VÁzQuez, op. cit. (nota 1), p. 239.

51 Contreras Gay, J.: "La reorganización militar en la época de la decadencia española (1640-1700) “, Millars: Espai i historia, 26 (2003), p. 147.

52 Vid. Fernández Cortizo, C. J.: "Población rural, mundo urbano y migraciones", en Historia de la Galicia Moderna, Santiago de Compostela, Universidade de Santiago de Compostela, 2012, pp. 39 y ss.

53 Rodríguez Hernández, op. cit. (nota 2), 2007, pp. 217-218.

54 Para el caso alavés y guipuzcoano vid., Truchuelo García: art. cit. (nota 47), pp. 254 y ss. Para Asturias y las Cuatro Villas: vid. Rodríguez HernÁndez: op. cit. (nota 47), pp. 236 y ss. En el Reino de Aragón partían de un sistema similar en el que las diferentes localidades contribuían a través de un repartimiento inicial que se hacía entre las "sobrecullidas", circunscripciones que componían una división administrativa con funciones de origen recaudatorio, comparable a la distribución territorial de los partidos gallegos. SOLANO CAMÓN, E.: "Formas de reclutamiento en la movilización de Aragón durante la Guerra dels Segadors (1640-1652) ", Obradoiro de Historia Moderna, 15 (2006), p. 183.
} 
trabas en comparación con aquellas acometidas por agentes externos a la localidad en cuestión. Precisamente, durante la segunda mitad del siglo XVII la corona conseguiría del Reino de Galicia 20.000 hombres $^{55}$, en su mayor parte para la defensa de Flandes, y durante la Guerra de Sucesión $7.000^{56}$, entre los que estaban los 2.000 que fueron a América.

Siempre que la tramitación del servicio se hacía a través de la negociación entre la corona y las Juntas, en estas también se ajustaba el reparto de los soldados entre las siete provincias en base al sistema de tercias y sextas partes -Tabla 1. Se trataba de una proporción empleada en origen para los prorrateos de las cargas fiscales - tomando como baremo el volumen demográfico -, que a partir de 1637 fue aplicada también en los cupos de soldados con los que tenía que colaborar cada provincia evitando así cualquier tipo de disputa o agravio ${ }^{57}$. De este modo se establecía una clara diferenciación entre tres provincias mayores -Santiago, Ourense y Lugo- y cuatro menores -Betanzos, Mondoñedo, Tui y A Coruña-, hecho que quedaba igualmente reflejado en el número de patentes de las que cada ciudad podía disponer.

Tabla 1. Repartimiento provincial de las reclutas de Galicia por las Juntas del Reino (16781705).

\begin{tabular}{|l|c|c|c|c|}
\hline Provincia & $\mathbf{1 6 7 2}$ & $\mathbf{1 6 7 4}$ & $\mathbf{1 6 7 8}$ & $\mathbf{1 7 0 2}$ \\
\hline A Coruña & 90 & 90 & 63 & 121 \\
\hline Betanzos & 92 & 100 & 91 & 181 \\
\hline Lugo & 170 & 90 & 167 & 333 \\
\hline Mondoñedo & 91 & 110 & 91 & 181 \\
\hline Ourense & 171 & 200 & 167 & 333 \\
\hline Santiago & 352 & 400 & 334 & 666 \\
\hline Tui & 96 & 90 & 91 & 181 \\
\hline Total: & 1.062 & 1.070 & 1.004 & 2.000 \\
\hline
\end{tabular}

Fuentes: RODRÍGUEZ HERNÁNDEZ, op. cit. (nota 8), 2011, p. 265; AJRG, vol. XII, 30/ IV/1702, 101-A, p. 276.

Una vez establecido este primer reparto, las encargadas de la recluta pasaban a ser cada una de las siete ciudades, responsables de sus respectivas áreas de influencia entre las que se volvían a establecer cupos en función del número de vecinos, tomando como punto de referencia los partidos, base territorial sobre la que se repartían las diferentes cargas fiscales de la monarquía. Se trataba, al fin y al cabo, de un método que

\footnotetext{
55 Rodríguez HernÁndeZ, op. cit. (nota 2), 2007, p. 266.

56 Todo ello sin tener en cuenta la movilización de milicias para la defensa de lo propio y las sucesivas reclutas para la restitución de las bajas.

57 Artaza Montero, op. cit. (nota 21), p. 271.
} 
se asemejaba a la fórmula de la quinta o de la circunscripción ${ }^{58}$. En el caso de la provincia de Tui, el repartimiento del servicio de 1702 se hizo siguiendo este esquema.

Si tomamos como ejemplo la distribución del servicio del chapín de la reina de $1701^{59}$, cuyo objeto era el de sufragar los costes del casamiento real, y comparándola con el número de soldados que cada partido debía satisfacer ${ }^{60}$, encontramos unos porcentajes de participación similares -Tabla 2.

Tabla 2. Repartimientos en la provincia de Tui: servicio del Chapín de la reina de noviembre de 1701; leva de 1702.

\begin{tabular}{|c|c|c|c|c|}
\hline Partido & Reales & $\%$ & $N^{0}$ Soldados & $\%$ \\
\hline A Guarda & 1.050 & 5,31 & 8 & 4,47 \\
\hline Baiona & 140 & 0,71 & 2 & 1,12 \\
\hline Barrantes & 805 & 4,07 & 10 & 5,59 \\
\hline Bouzas & 476 & 2,41 & 5 & 2,79 \\
\hline Oia & 490 & 2,48 & - & - \\
\hline Crecente & 1.820 & 9,20 & 17 & 9,50 \\
\hline Mos & 682 & 3,45 & 4 & 2,23 \\
\hline O Covelo & 700 & 3,54 & 9 & 5,03 \\
\hline O Porriño & 1.470 & 7,43 & 12 & 6,70 \\
\hline Reboreda & 805 & 4,07 & 10 & 5,59 \\
\hline Redondela & 280 & 1,42 & 2 & 1,12 \\
\hline Salceda & 1.330 & 6,72 & 10 & 5,59 \\
\hline Salvaterra & 1.820 & 9,20 & 16 & 8,94 \\
\hline Sobroso & 3.220 & 16,28 & 30 & 16,76 \\
\hline Soutomaior & 1.120 & 5,66 & 12 & 6,70 \\
\hline Tebra & 140 & 0,71 & 2 & 1,12 \\
\hline Tui & 140 & 0,71 & 2 & 1,12 \\
\hline Val do Fragoso & 1.260 & 6,37 & 11 & 6,15 \\
\hline Val Miñor & 1.750 & 8,88 & 14 & 7,82 \\
\hline Vigo & 280 & 1,42 & 3 & 1,68 \\
\hline Total & 19.778 & 100 & 179 & 100 \\
\hline
\end{tabular}

Fuentes: AHPPo, CT: L-822 (1701), f. 175r; L-823 (1702), ff. 86r-87v.

\footnotetext{
58 Desde finales del siglo XVI, y al calor de los cambios en el modelo de recluta, empezaron verse los primeros intentos de este tipo de sistemas de reclutamiento. ThOMPSON, op. cit. (nota 15), p. 23.

59 AHPPo, CT, L-822 (1701), 9/VII/1701, f. 175r.

60 AHPPo, CT, L-823, 16/III/1702, f. 86r-87v.
} 
En el cómputo general, en torno al 50\% del valor total de los servicios -un 50,96 \% del chapín y un 49,15\% de la leva- eran asumidos por cinco, los más poblados y extensos, de los 19 partidos que componían el total de la provincia: Sobroso, Salvaterra, Crecente, Val Miñor y O Porriño ${ }^{61}$. En el lado opuesto se situaban las pequeñas villas -Vigo, Redondela, Tui y Baiona- que, a excepción de Bouzas que contaba con un número de parroquias mayor, apenas sumaban juntas el $5 \%$ de los aportes en hombres y/o dinero. Este hecho no deja de ser ilustrativo de la realidad del sistema urbano gallego de Antiguo Régimen, caracterizado por la debilidad demográfica de los distintos núcleos, sobre todo si se los compara con la red castellana. No hay que olvidarse tampoco de que algunas localidades veían atemperados sus cupos con un número menor de reclutas porque tenían que cumplir también con las levas de marineros, lo que significaba para estas poblaciones una doble línea de contribución humana para los ejércitos de la monarquía. Tal era el caso de las villas de Vigo, Redondela y Bouzas.

Tabla 3. Reparto de las levas entre los partidos de la provincia de Tui (1702-1706).

\begin{tabular}{|c|c|c|c|c|c|c|c|c|}
\hline Partido & \multicolumn{2}{|c|}{1702} & \multicolumn{2}{|c|}{1703} & \multicolumn{2}{|c|}{1705} & \multicolumn{2}{|c|}{1706} \\
\hline & $\mathrm{N}^{o}$ & $\%$ & $\mathrm{~N}^{o}$ & $\%$ & $\mathrm{~N}^{\mathrm{o}}$ & $\%$ & $\mathrm{~N}^{\mathrm{o}}$ & $\%$ \\
\hline A Guarda & 8 & 4,47 & 4 & 4,40 & 22 & 6,09 & 120 & 6 \\
\hline Baiona & 2 & 1,12 & 1 & 1,10 & 2 & 0,55 & 12 & 0,6 \\
\hline Barrantes & 10 & 5,59 & 5 & 5,49 & 20 & 5,54 & 120 & 6 \\
\hline Bouzas & 5 & 2,79 & 3 & 3,30 & 9 & 2,49 & 45 & 2,25 \\
\hline Oia & - & - & - & - & 10 & 2,77 & 55 & 2,75 \\
\hline Crecente & 17 & 9,50 & 8 & 8,79 & 34 & 9,42 & 170 & 8,5 \\
\hline Mos & 4 & 2,23 & 2 & 2,20 & 8 & 2,25 & 50 & 2,5 \\
\hline O Covelo & 9 & 5,03 & 5 & 5,49 & 16 & 4,43 & 90 & 4,5 \\
\hline O Porriño & 12 & 6,70 & 6 & 6,59 & 27 & 7,48 & 140 & 7 \\
\hline Reboreda & 10 & 5,59 & 5 & 5,49 & 18 & 4,99 & 100 & 5 \\
\hline Redondela & 2 & 1,12 & 1 & 1,10 & 2 & 0,55 & 12 & 0,6 \\
\hline Salceda & 10 & 5,59 & 4 & 4,40 & 24 & 6,65 & 135 & 6,75 \\
\hline Salvaterra & 16 & 8,94 & 8 & 8,79 & 28 & 7,76 & 160 & 8 \\
\hline Sobroso & 30 & 16,76 & 16 & 17,58 & 53 & 14,68 & 302 & 15,1 \\
\hline Soutomaior & 12 & 6,70 & 6 & 6,59 & 24 & 6,65 & 140 & 7 \\
\hline Tebra & 2 & 1,12 & 1 & 1,10 & 4 & 1,10 & 20 & 1 \\
\hline Tui & 2 & 1,12 & 1 & 1,10 & 2 & 0,55 & 12 & 0,6 \\
\hline
\end{tabular}

61 Con diferencia era Sobroso el partido que estaba más gravado en el conjunto de los datos provinciales, con más de un $16 \%$ del total, seguido de lejos por los restantes partidos nombrados con unos niveles de participación que oscilaban entre el $9 \%$ y el $6 \%$. 


\begin{tabular}{|l|c|c|c|c|c|c|c|c|}
\hline Val do Fragoso & 11 & \multicolumn{1}{c}{6,15} & \multicolumn{1}{c}{6} & \multicolumn{1}{c}{6,59} & 26 & \multicolumn{2}{c|}{7,20} & \multicolumn{2}{c|}{145} & 7,25 \\
\hline Val Miñor & 14 & 7,82 & 7 & 7,69 & 30 & 8,31 & 160 & 8 \\
\hline Vigo & 3 & 1,68 & 2 & 2,20 & 2 & 0,55 & 12 & 0,6 \\
\hline Total & 179 & 100 & 91 & 100 & 361 & 100 & 2.000 & 100 \\
\hline
\end{tabular}

Fuente: AHPPo, CT: L-823 (1702), ff. 86r-87v; L-824 (1703), f. 64r; L-826 (1705), f. 78r; L-827 (1706), f. 153r.

La proporción entre los partidos se mantuvo a lo largo de toda la Guerra de Sucesión y, presumiblemente, se habría aplicado del mismo modo en periodos anteriores. Pese a ella tampoco se trata de una redistribución con proporciones inmutables, toda vez que los repartos se ajustaban en función de la coyuntura del momento -Tabla 3. Entre 1702 y 1706 la contribución de las pequeñas entidades urbanas tudenses pasó del $5 \%$ al 2,4\% sobre el total. Este aligeramiento de la carga responde, en parte, a una corrección por el peso que soportaban estos núcleos, pues eran los encargados de mantener los gastos generados por los alojamientos de tropas, que hasta bien entrado 1707 fueron casi permanentes ${ }^{62}$. Del mismo modo, se observa un incremento del peso contributivo sobre los partidos situados en el cuadrante septentrional y occidental -véase Val do Fragoso o Sotomaior-, frente a los limítrofes con Portugal, como Salvaterra o Crecente, más afectados por el impacto de la actividad militar.

En el momento en el que la cabeza de provincia había dispuesto lo que a cada partido le correspondía en cuanto a la recluta de hombres, la responsabilidad recaía en los municipios. El proceso de provincialización en el sistema de reclutamiento había otorgado un protagonismo central a estas entidades locales en lo que se refiere a la gestión de cualquier tipo de movilización para la guerra ${ }^{63}$, ya que, en última instancia, eran las que decidían cuáles de sus vecinos pasaban a engrosar las filas del ejército, además de costear los gastos de la leva. Hasta bien entrado el siglo anterior la administración y ejecución de la leva había correspondido también a los capitanes y cabos de milicia, sin embargo, por la multitud de "excessos y agravios" que habrían cometido, en las Juntas del Reino de 1642, se terminó proponiendo que los hombres se sacaran por todas "las pilas [bautismales] que tienen las provinçias, dando cada vna la parte que le tocare conforme el número de gente que tuviese y que esto fuese con interbençión de las Justicias de cada ciudad [...] y se aorrarían las molestias y agravios que se asen a sus naturales" ${ }^{4}$. En el caso de la leva de 1702, la ejecución de la recluta no debió de distar mucho de las experiencias vividas en pasadas ocasiones, salvo por el hecho de que la prisión se debía llevar a cabo con la mayor cautela y secreto, hecho exigido por tratarse de unos preparativos militares previos a la declaración formal de guerra que se esperaba pero no se deseaba provocar ${ }^{65}$.

62 Lago Almeida, H.: "La actividad militar y el impacto de la guerra en la Galicia sudoccidental. Una aproximación a la primera etapa borbónica (1700-1714)", en SERRANO, E. (coord.): De la tierra al cielo. Líneas recientes de investigación en Historia Moderna, Zaragoza, CSIC., 2013, pp. 399-412.

63 Contreras Gay, op. cit. (nota 15), pp. 145 y ss.

64 AJRG, Vol. V, 27/III/1642, 8-A, p. 121; 21/VII/1642, 9-A, p. 129.

65 AHPPo, CT, L-823, 10/III/1702, f. 79r. Cf. Eiras Roel, op. cit. (nota 29), p. 41. 
Mapa 1. Distribución de la recluta en la provincia de Tui (1702). ${ }^{66}$

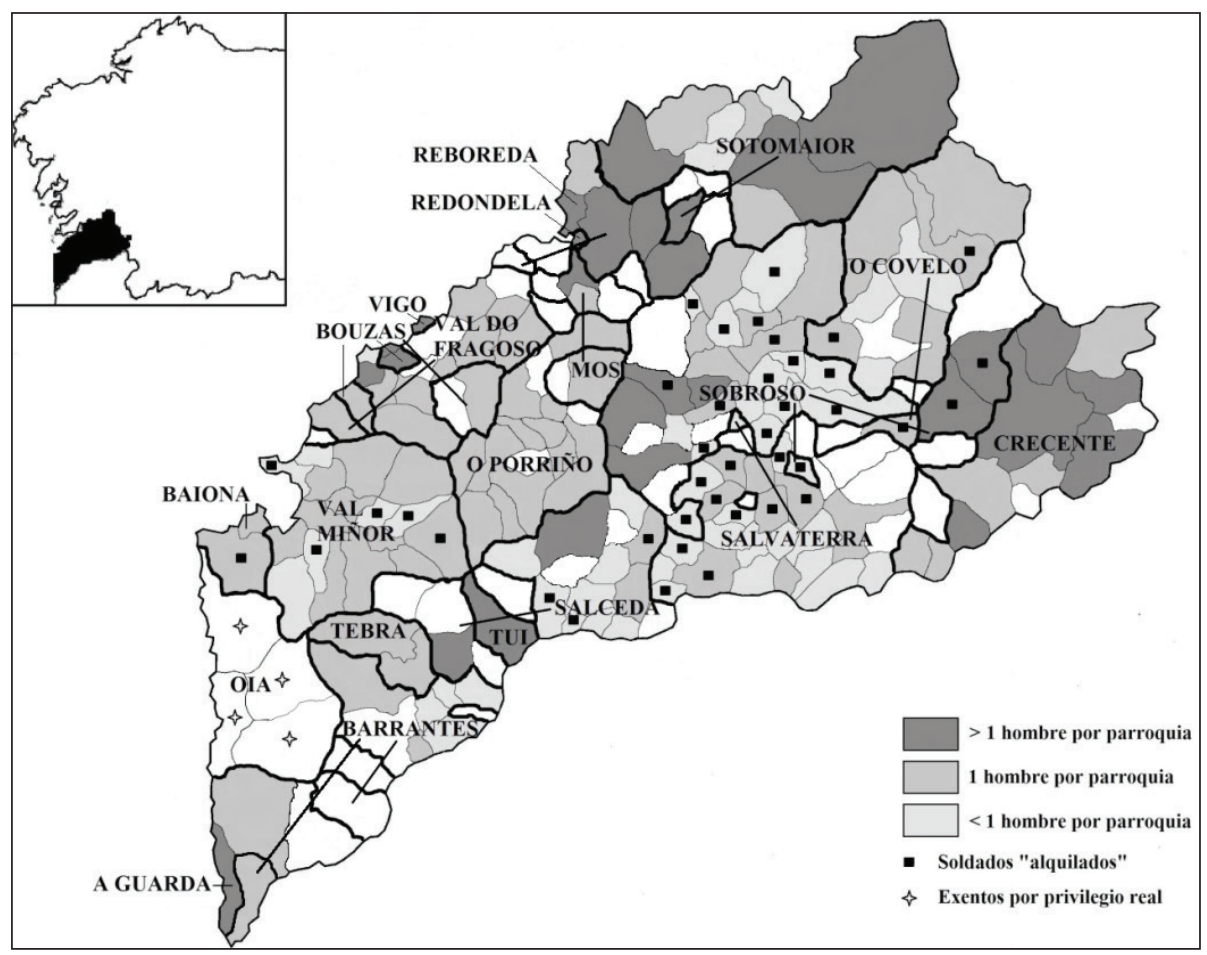

Fuentes: AHPPo, CT, L-823 (1702), ff. 105r-188v.

Lo habitual era que las diferentes justicias locales seleccionasen a los individuos que servirían como soldados. Una vez prendidos eran enviados a Tui en donde pasaban un primer reconocimiento físico. Superado este, pasaban al punto de reunión, en este caso A Coruña, desde donde la armada francesa los trasladaría a las Indias. En este plano, el procedimiento y la responsabilidad de la recluta variaba. Regularmente los gobiernos municipales elegían a un integrante de los mismos, que bien podía ser uno de sus regidores o el procurador general, como encargado de la recluta. Esta norma puede ser aplicable en aquellos partidos cuyos núcleos urbanos tenían

66 Elaboración propia a partir de: Torres LunA, M. P. y PAzo LABRAdor, A.: Parroquias y arciprestazgos de Galicia, Santiago de Compostela, Universidade de Santiago de Compostela, 1994. Se ha procurado aproximar la división parroquial a la realidad de principios del siglo XVIII a partir de los datos de: Río BARXA, F. J. y Magdalena Vidal, M. V.: "Mapa de las jurisdicciones de la provincia de Tui en el siglo XVIII", en Homenaje de la Facultad de Geografía e Historia a los profesores D. Manuel Lucas Álvarez y D. Ángel Rodríguez González, T. II, Santiago de Compostela, Universidade de Santiago de Compostela, 1987, pp. 544-551; REY Castelao, O.: "La diócesis de Tuy en la época moderna", en Historia de las diócesis españolas. Santiago de Compostela. Tuy-Vigo, Madrid, Biblioteca de Autores Cristianos, 2002, pp. 576-583. La división de los partidos supone una aproximación, ya que por la falta de datos o por la falta de un estudio de la cartografía de los mismos que conozcamos, hemos optado por dejar en blanco y fuera de la división territorial aquellas parroquias de las que no disponemos de datos fiables. 
un limitado territorio dependiente -Tui, Baiona, Redondela o Vigo. Sin embargo, la mayor parte de los partidos tenían un amplio número de parroquias integradas en su circunscripción, y en algunos casos la prisión de soldados por parte de la cabeza de partido era inviable, lo que obligaba a implicar en la recluta a las parroquias o, en determinadas ocasiones, a jurisdicciones con cierta entidad ${ }^{67}$. Prueba de ello la tenemos en los registros de soldados que se iban remitiendo desde los diferentes puntos de la provincia a la ciudad de Tui. En ningún caso, salvo en los anteriormente citados, el cupo de soldados de cada uno de los partidos llegaba de una vez, sino que la cabeza de partido los remitía por su cuenta y las restantes parroquias de la mano de un juez o del mayordomo en cuestión ${ }^{68}$. No cabe duda de que esta atomización de las reclutas permitía una redistribución eficaz de los costes materiales y humanos, en tanto que cada parroquia y/o justicia se hacía cargo de la prisión y mantenimiento del soldado.

Esta profusa distribución queda reflejada una vez volcamos los datos en un mapa del conjunto de las parroquias de la provincia de Tui -Mapa 1. Dado que la documentación permite determinar la feligresía por la que se presenta un soldado en el $94 \%$ del total del cupo de hombres adjudicado a la provincia, la representatividad del mapa resulta digna de mención. Se estima que para 1702 habría en la provincia de Tui un número aproximado de 216 parroquias -de las cuales 49 no aparecen en los registros de la presente leva- además de las dependientes del partido de Oia que estaban exentas, aunque no siempre, por privilegio real desde $1676^{69}$. Sin embargo, 163 -un $75,6 \%$ - contribuyeron, en hombres y/o numerario, en la ejecución de la recluta. Una gran suma de ellas aportaba un único soldado en representación de su feligresía, salvo aquellas que poseían un volumen poblacional y territorial considerable, situadas mayoritariamente en la mitad este de la provincia, de las cuales una parte importante será objeto de varios procesos de desfragmentación en los siglos XVIII y XIX ${ }^{70}$, lo que ejemplifica la entidad de las mismas. En cambio, en el cuadrante central y sur del territorio se concentran un significativo número de parroquias que aportan menos de un soldado por cada una, consecuencia no tanto de la falta de población como de la ridícula extensión territorial de algunas unidades, que en casos extremos superaban con poco los 5 o $7 \mathrm{~km}^{271}$. En este sentido, la suavidad de la carga que se observa en la trama de las feligresías emplazadas en la raya con Portugal, constatan un cierto basculamiento de la carga hacia el territorio interior como una medida paliativa ante la obligación de mantener en armas permanentemente a las milicias en este cuadrante fronterizo de la provincia. No es casualidad que en 1705, avanzada ya la contienda y con la participación del vecino luso en el conflicto, el capitán general llamase la atención sobre este hecho a la hora de redistribuir esfuerzos en los repartos de hombres rebajando el número de soldados a aquellos partidos colindantes con Portugal,

\footnotetext{
67 Por ejemplo las jurisdicciones de las Achas o de Pesegueiro.

68 En el caso del Partido de Porriño separadamente y en fechas diferentes, los soldados fueron presentados en Tui por: Lorenzo Rodríguez, mayordomo de Chenlo; Domingo Mourno, mayordomo de Atios; D. Diego Pérez de Velasco, juez de Santantuiño; Alonso de Lago, mayordomo de Dornelos y por Luis de Barros, procurador general del Porriño. AHPPo, CT, L-823, ff. 105r-113v.

69 AHPPo, CT, L-809, VI/1689, f. 118 r.

70 Tal es el caso de Berduciño, Sendelle o Valeixe. Cfr. Rey Castelao, op. cit. (nota 68), p. 577 y ss.

71 Ibidem, p. 576.
} 
así como a los "parajes zercanos al mar, por la vigilancia con que asisten"72. Las instrucciones iban más allá, al indicar que los partidos hicieran lo propio con aquellas parroquias inmediatas a los límites de la provincia.

Por norma general, después de ser seleccionados, los soldados eran prendidos y llevados a la prisión pública en donde se les recluía mientras no se les desplazaba al lugar requerido. Se solía seleccionar a los guardias que se debían de encargar del traslado de los hombres, en el caso de Vigo o de Baiona dos o tres por cada soldado, uno de los cuales debía ir esposado al recluta ${ }^{73}$. Desde el momento en el que eran apresados, hasta su llegada a Tui, los gastos que pudiesen generar-sueldos, guardias, manutención, etc- tenían que ser sufragados por las autoridades locales ${ }^{74}$, que a su vez redistribuían entre sus vecinos.

En ocasiones los sujetos seleccionados no cumplían con los requisitos prestablecidos para su apresamiento. La casuística de las objeciones podía ir desde un incumplimiento de los requerimientos físicos, hasta que fuese hijo de viuda o la edad del candidato. Así, el soldado una vez partía de su vecindad tenía que superar dos cribas: en primer lugar en la ciudad de Tui, y en segundo en A Coruña donde seguramente los exámenes fuesen mucho más estrictos. De hecho, el 29,8\% de los hombres que aparecen en los registros de salida de Tui hacia Coruña no dejaron ningún rastro documental en la Veeduría y Contaduría de la gente de guerra. Salvo un apresado, que se especifica que logró huir durante su traslado a la capital herculina, los demás no debieron de superar las condiciones mínimas para ser aceptados como soldados. En estos casos, la localidad de origen del sujeto tenía que reiniciar el proceso reclutador, multiplicando el esfuerzo económico derivado de la leva.

\subsection{CARACTERÍSTICAS DE LOS RECLUTADOS}

Partiendo de apreciaciones cualitativas y de las directrices que marcaba el gobernador del reino, que aludían a las características que debería tener el hombre reclutado, el perfil de los reclutas tudenses no se aleja de la típica imagen del soldado bisoño. El Príncipe de Barbanzón prevenía de "no echar mano de viejos, casados, hijos únicos de viudas ni gente apta con ejerçiçio en la cultura del canpo", en favor de aquellos que "fueren de menos utilidad en ella, bagamundos, reboltosos de mal bibir y que ayan serbido a su Ma.d y salídose sin liçençia", siempre y cuando superasen los 18

72 AHPPo, CT, L-826 (1705), 10/I/1705, ff. 163v-164r.

73 En el caso de Baiona se preocupaban también de vestirlos decentemente: "respecto de allarse preso en la cárcel real de esta vi.a Ant.o Gonz.s p.a ir por soldado [...] y p.a remitirlo a pasar la Biduría a la çiudad de Tuy y presentarlo en la de la Coruña acordaron se vista decentemente". Archivo Municipal de Baiona (AMB), Fondo Histórico, L-30, 1/IV/1702, s.f.

74 Así se hacía cómputo de los gastos en el caso de Vigo: "asistí a los soldados a cada vno a tres r.s cada día. A las tres guardias que fueron sueltas a tres r.s. A las otras tres guardas que fueron esposados con los soldados a quatro r.s. Veinte y quatro r.s que lleuó el ss.o Pablo de Bugarín que dijo tocar por la presenta.on de dhos. tres soldados y seis que lleuó dho. ss.o por dar la guía y ttestimonio de auerse recurido dhos. soldados. Más treinta y seis r.s que se dieron a dho. Gregorio Piñeiro para los gastos de su persona y cauallería. [...] Con más seis r.s que di a dhos. soldados desde que llega.n de la ciudad de Tuy a esta villa asta que partieren p.a la ciudad de la Coruña. Que pareze ynportan dhos. gastos ciento y setenta y quatro r.s que juntos con los de la leua de la Coruña que ynporta trescientos y setenta y tres r.s". Archivo Municipal de Vigo (AMV), Actas del Ayuntamiento de Vigo (AAV): PLE 15-L, 10/IV/1702, f. 15r-v. 
años de edad ${ }^{75}$. Por tanto, lo ideal era un individuo soltero cuya actividad económica no estuviese ligada a la agricultura. A mayores, se pretendía que el servicio gravitara en mayor medida sobre los sectores marginales de la sociedad, los que al fin y al cabo eran prescindibles para su conjunto, a la vez que se obviaban las capacidades para la guerra de los posibles reclutas. No es de extrañar que con la práctica del modelo de reclutamiento forzoso se hubiese generalizado la presencia del soldado "bisoño" y forzado sobre la presencia de militares profesionales, repercutiendo esto en la calidad militar de los hombres destinados para la guerra ${ }^{76}$. Son clarificadoras las declaraciones que hacía el gobernador de Cartagena de Indias a la llegada de las cinco compañías que plausiblemente habían formado parte de los dos tercios enviados desde Galicia:

Las cuales he hecho repartir entre los vecinos para que con más cuidado se hagan al país, porque la experiencia ha mostrado que, no teniéndole los más de los que pasan a esta América, mueren; acúdeseles a los patrones con el socorro de dos reales al día y aseguro a V.M. que de este número serán muy pocos útiles, antes sí comerán el pan de V.M. sin mérito por ser gente incapaz de disciplina militar, reclutados por fuerza y sacados del $\operatorname{arado}^{77}$.

La documentación municipal de Tui arroja luz sobre esta cuestión desde dos puntos de vista. El primero se apoya en un informe en el que figuran los soldados que en la leva de 1702 fueron guiados desde Tui a la ciudad de A Coruña. Consiste en un registro a través del cual podemos conocer el nombre del reclutado; si tiene padres conocidos y en tal caso sus nombres y apellidos; la vecindad; una breve descripción física y su edad. No se trata de un registro completo, dado que solo recoge 94 casos. El segundo de los registros nos da la perspectiva de la Veeduría y Contaduría de Guerra en A Coruña, desde donde admitían a sueldo a los hombres levados. En este caso la información es parca en contenidos: nombres y apellidos de los reclutados; parroquias y/o partidos que "representan", junto a la fecha de llegada. Sin embargo, el número de individuos cubre el $94,4 \%$ del total de las reclutas.

En el primer caso, pese a cubrir solo el 52,5\% del total del cupo teórico que le tocaba a la provincia, el conjunto de la información obtenida resulta digna de análisis. Por lo que respecta a la edad, nos encontramos con un colectivo joven que rondaba los 22,5 años, una media baja si se la compara con los datos de otros ejércitos europeos del mismo periodo ${ }^{78}$. El 52,1\% no sobrepasaban los 20 años y tan solo un 4,2\% decían tener más de 30, distribuyéndose los restantes entre los 20 y los 30, con una pérdida de peso relativo a medida que se aproximan a esta última cifra, un hecho que obedece a la exigencia de soltería -Gráfico 1-. Se observa una clara concentración de casos en el grupo de edad de 20 años y mucho menor, pero destacable, en el de los 30 , sintomático de que el conocimiento de la edad exacta no siempre era plausible, sí en todo caso una aproximación. En general, es un grupo con una fuerte homogenei-

\footnotetext{
75 AHPPo, CT, L-823, 10/III/1702, f. 78r-v.

76 Contreras Gay, op. cit. (nota 15), p. 148 y ss.

77 Ruiz Rivera, op. cit. (nota 45), p. 303.

78 TAllett, op. cit. (nota 15), pp. 85-86.
} 
dad generacional, lo que debió de ser un factor relevante de cohesión, de sentimiento de camaradería, aunque también un previsible foco de indisciplina y, sobre todo, de inexperiencia ${ }^{79}$.

Gráfico 1. Distribución de los soldados reclutados en la provincia de Tui por cohortes (1702).

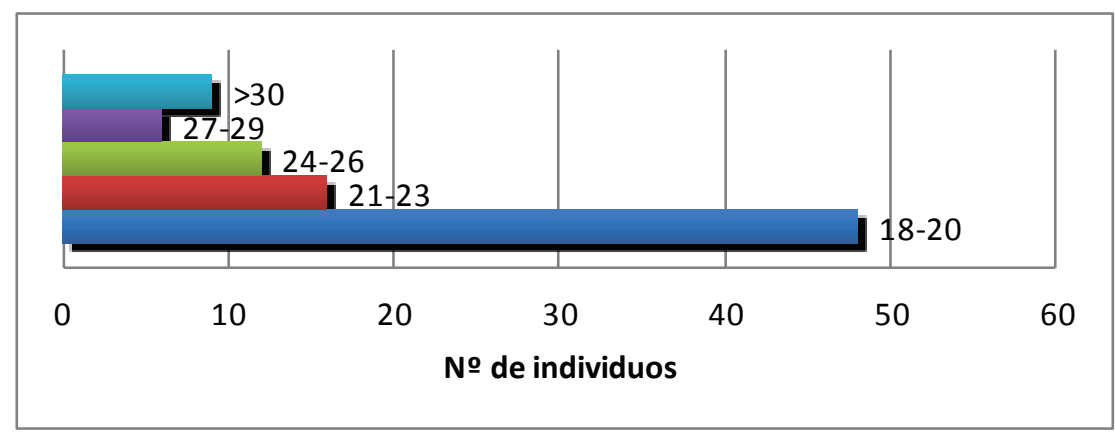

Fuente: AHPPo, CT, L-823 (1702), ff. 105r-113v.

Desde el punto de vista de la procedencia de los reclutados, el 95,7\% eran oriundos del Reino de Galicia, de los cuales el $98 \%$ eran vecinos de alguno de los partidos de la provincia de Tui. Cada uno de los hombres era presentado por una o varias parroquias o por un partido. Lo habitual era que un mismo reclutado representase a dos vecindades siendo natural de una de ellas. En este sentido, los cupos se redistribuían entre las parroquias en función del número de vecinos, por lo que era habitual que a una vecindad le correspondiese "medio soldado". En estos casos se sobrentiende que una parroquia contribuía con la prisión del levado y la segunda con los gastos derivados de la recluta. Este fue el caso de Antonio Diego de Regueira, natural de Reboreda, y presentado por tres feligresías: Cesantes, Amoedo y la misma Rebore$\mathrm{da}^{80}$. El hecho de que la mayor parte de los individuos fuesen oriundos de la zona se explica en parte por la obligación que tenían las diferentes feligresías o jurisdicciones de presentar sujetos nacidos en sus territorios. Prueba de ello es que varios candidatos no eran admitidos como tales por no haber nacido en la zona, así, por ejemplo, en una leva ejecutada en 1689 para Flandes, el apresado Diego de Telas, reclutado por la villa de Baiona, no era admitido como representante de esta villa, pero sí lo era por la jurisdicción de Barcia de Mera de la que era natural ${ }^{81}$. Con tales presupuestos, $y$ sobre el total de los reclutados, se puede comprender que en torno a un $80 \%$ habrían nacido en la provincia tudense. El cupo restante, como se verá, participa en calidad de substitutos, cuyo origen geográfico desconocemos.

Que los hombres apresados careciesen de práctica militar era un hecho a todas luces visible, no así la condición de marginados, vagabundos o revoltosos. Es revela-

\footnotetext{
79 Cfr. Thompson, op. cit. (nota 15), p. 35.

80 AHPPo, CT, L-823, ff. 114-188v.

81 AHPPo, CT, L-809, 9/V/1689, f. 141r.
} 
dora la información que se nos muestra en los tres sujetos reclutados por el concejo de Vigo. Pese a que la documentación no da pie a juzgar si se trataba o no de hombres con un tipo de vida "cuestionable", lo que se observa es una extracción social humilde, por lo menos en lo que se deriva del origen familiar de estos: Juan de Nandín, "hixo de Fran.ca de Salinas, muger solt.a, que le tubo y no se saue de quien"; Juan Dacuña, "mozo que se crio en esta villa, al que no se le conosen lexittimos padres"; y Domingo Ignacio de Abendaño, que afirmaba "ser hixo bastardo de D.n Ju.n de Abendaño" 82 . Los tres eran hijos bastardos o no reconocidos por sus progenitores, lo que les habría granjeado una posición socioeconómica lateralizada en el conjunto de la villa y, en consecuencia, los convertía en prototipos claros para las reclutas forzosas. Sin embargo, esta visión no cuadra con los datos generales para el conjunto de la provincia, en los que el $70,2 \%$ de los hombres tienen padres conocidos y con vida; a un $12,7 \%$ le falta uno de los dos, bien por qué se desconoce o por fallecimiento; $\mathrm{y}$, por último, un $15,9 \%$ de los reclutados afirman no tener padres.

En el cómputo global de los que fueron recibidos a sueldo en la Veeduría y Contaduría de gente de guerra -un 94\% del total de los soldados que teóricamente tendría que aportar Tui-, llama la atención el peso relativo de los reclutados que aparecían bajo la denominación de "alquilados", un 20,12\%. A finales del mes de marzo, cuando ya se había superado la fecha límite para la ejecución de la leva, la capital tudense alertaba a su representante en las Juntas de que no se había cubierto ni la décima parte de los soldados que le tocaban, consecuencia de "auerse pasado ai muchos días la gente a propóssito para el cumplim.to de la leua al r.no de Portugal" ${ }^{13}$. Como medida disuasoria el regimiento de Tui había resuelto que por vía imperativa se obligase a los padres con tres hijos o más a entregar a uno de ellos para el real servicio. De hecho se advertía que en las levas realizadas en Portugal se obliga a los padres a presentar a sus hijos como candidatos en las reclutas, una práctica que no se llevó a cabo en Galicia por los perjuicios que pudiese generar, a pesar de lo cual en la leva de 1703 sí se contemplós ${ }^{84}$.

Finalmente, en 1702 se obvió la posibilidad de presionar de este modo a los vecinos y se opta por "permitir a las justiçias executen p.a el referido cumplm.o lo que tuvieren por más conuenientte a sus naturales y v.s preuiniéndoles que las feligresías que determinan alquilarlos no se detengan en azerlo" ${ }^{85}$. Con esto se pretendía agilizar la recluta al mismo tiempo que para ciertas poblaciones se hacía más llevadero el servicio al poder contratar substitutos, lo que evitaba la incómoda situación de apresar a un vecino de la localidad. La oportunidad fue muy aprovechada, en total 39 feligresías se decantaron por seguir esta vía para cubrir el cupo que les había sido repartido.

El alquiler de reclutas era una práctica heredada del periodo anterior, al menos en las reclutas realizadas en los años 90 del siglo XVII parece haber sido lo habitual; sin

82 AMV, AAV: PLE 15-L, 27/III/1702, f. 11r.

83 AHPPo, CT, L-823, 31/III/1702, f. 98r.

84 AHPPo, CT, L-824, 28/III/1703, f. 72r.

85 AHPPo, CT, L-823, 31/III/1702, f. 100r-v. En algunos casos ya aventuraban esta posibilidad con anterioridad, así el concejo de Baiona animaba a la parroquia de Sta. María de Baiña y Baredo a acudir a la Veeduría y Contaduría de la gente de guerra de A Coruña en caso de no encontrar candidatos en la dicha feligresía. AMB, Fondo Histórico, L-30, 6/III/1702, s.f. 
embargo, en el contexto de la Guerra de Sucesión fue una vía de captación única. Esta posibilidad de aportar sustitutos no fue una práctica exclusiva de las autoridades gallegas, ya que se documentan otros casos en las reclutas ejecutadas en las Provincias Vascas. Más concretamente en la de Álava, en donde los encargados de buscar a los hombres "alquilados", además de las propias autoridades locales, eran particulares que pagaban a individuos dispuestos a ir a la guerra en su lugar, en su mayor parte forasteros o incluso familiares ${ }^{86}$.

En nuestro caso, resulta difícil establecer algún tipo de parámetro social para este grupo de soldados, ya que la única información que conocemos se limita a sus nombres y apellidos y la parroquia o vecindad por la que eran presentados. En principio cabe suponer que se alejaría de la imagen del soldado forzado, cuyo perfil estaría marcado por la inexperiencia militar y falta de interés, junto a unas elevadas tasas de deserción. Por el contrario, podemos esperar que se trate de un individuo que superaría la media de edad, que voluntariamente accede al servicio militar y, por último, que no sería ignorante en lo que a la práctica de las armas se refiere. En la mayor parte de los casos son alquilados en la ciudad de A Coruña, cuya importancia militar podría haber definido la existencia de algún tipo de "mercado" en el que individuos con cierta experiencia ofrecieran sus servicios a cambio de una prima. Cabe suponer, por lo tanto, que al igual que se habían creado las condiciones para la aparición de una élite gallega con cierto hábito en el arte de las armas, durante la segunda mitad del XVII también se habría gestado una tropa con experiencia militar, cuyas expectativas de vida se podrían haber visto deterioradas una vez desmovilizadas las unidades en las que servían.

\section{CONCLUSIONES}

En 1702, pese a no poder contar con la nominación de la plana mayor de la oficialidad y pese a un cambio repentino del destino de la recluta hacia América, la corona consiguió del reino de Galicia el servicio de 2.000 hombres que había pretendido desde un principio. La leva se efectuó a través de los instrumentos heredados del periodo anterior e introduciendo ciertos cambios que dejaban entrever las transformaciones que estaban por llegar. Lo cierto es que, a lo largo de toda la Guerra de Sucesión, Galicia seguiría contribuyendo a través de la creación de diferentes unidades militares, no solo para la defensa de lo propio, sino también para atender la presión de otros frentes, especialmente el extremeño. Sin embargo, a medida que las cargas se fueron haciendo más continuas, la postura de las Juntas se iría endureciendo hasta protagonizar verdaderos enfrentamientos con los poderes monárquicos. Con todo y con eso, las siete ciudades representadas disponían de un entramado que les permitía redistribuir hasta el último rincón del reino el esfuerzo necesario para la creación de las unidades.

Desde el punto de vista del sistema de recluta, la centralidad de los poderes locales como ejecutores últimos de la leva se mantuvo. Cabe diferenciar en este punto a las siete capitales gallegas de las que no lo eran, en tanto que las primeras contaban con

86 Rodríguez HernÁndez: op. cit. (nota 47), p. 246. 
la posibilidad de nombrar a la oficialidad, obteniendo por tanto una cierta contraprestación, con la que se beneficiaba en la mayor parte de los casos a las familias de los propios integrantes de los gobiernos concejiles o a estos mismos. Por el contrario, los restantes poderes de las provincias, en muchas ocasiones, se veían privados de esta posibilidad. Aunque de entrada no provocó ningún conflicto, sí es posible que constituyera un elemento más en el enrarecimiento de las relaciones entre villas, jurisdicciones y capitales a medida que la contienda avanzaba, especialmente en el caso tudense donde la presión de la actividad militar sobre sus vecinos estuvo más latente.

Se ha constatado también la relevancia operativa de las parroquias y de ciertas jurisdicciones con entidad en el conjunto del entramado reclutador, dado que eran jueces y mayordomos los encargados del traslado de los seleccionados y, con toda seguridad, de elegirlos entre todos los vecinos. De tal manera que la contribución de hombres para los ejércitos se convertía en un "impuesto" equiparable y extensible a la población rural y la población urbana, esta última sujeta a un gobierno municipal desde el cual la ejecución de la leva sobre su población parecería en principio más factible. En este sentido, es ilustrativo que el esfuerzo humano y material prestado desde la provincia de Tui hubiese sido distribuido entre 3 de cada 4 feligresías.

Desde el punto de vista social, el perfil del individuo reclutado responde a la de un joven de origen gallego, con ambos padres vivos e ignorante en el manejo de las armas. Salvo casos aislados, no se ha podido demostrar la recluta masiva de "vagos y maleantes", en parte, lo podemos explicar porque el grueso de la recluta basculó sobre la población rural mientras que las bolsas de marginalidad son propias de los ambientes urbanos. No obstante, la documentación nos permite matizar también la visión del "bisoño", general a todos los individuos levados por la vía de la recluta forzosa, y es que 2 de cada 10 soldados eran pagados como sustitutos, cuyas características se vincularían en mayor medida con la de un soldado voluntario y por tanto, en principio, con un nivel de profesionalidad mayor. Un número nada desdeñable de parroquias terminaron por acogerse a esta opción de presentar un hombre "alquilado" evitando así no solo el apremio de ejecutar la recluta a tiempo, sino también liberando la tensión y el posible conflicto de tener que seleccionar a uno de sus vecinos para un viaje cuyo regreso no estaba asegurado. 